\title{
MODELOS DE REPRESENTACIÓN DEL INDÍGENA EN EL DISCURSO CIENTÍFICO/ERUDITO. UNA APROXIMACIÓN DESDE LOS ARTÍCULOS PUBLICADOS EN CHILE DURANTE LAS TRES PRIMERAS DÉCADAS DEL SIGLO XX
}

\author{
MODELS OF REPRESENTATION OF THE INDIGENOUS PEOPLE IN THE \\ SCIENTIFIC/SCHOLARLY DISCOURSE. AN APPROACH BASED ON SCIENTIFIC \\ ARTICLES PUBLISHING IN CHILE DURING FIRST THREE DECADES OF THE \\ $2 O^{T H}$ CENTURY
}

Héctor Mora Nawrath ${ }^{1}$ y Gertrudis Payàs Puigarnau ${ }^{2}$

\begin{abstract}
El objetivo del presente artículo, que presenta resultados de dos proyectos de investigación, fue identificar las representaciones de alteridad presentes en el discurso científico/erudito sobre la población indígena en Chile durante las tres primeras décadas del siglo XX. El periodo definido resulta de interés, dado que en él se dio inicio al proceso de institucionalización de una ciencia antropológica referida al estudio de los pueblos indígenas en Chile (cultura material, antropometría, costumbre y lengua), lo que se manifiesta en la fundación de museos, sociedades científicas y la creación de revistas especializadas. Junto con describir algunos aspectos que remiten a las condiciones materiales y sociales desde las cuales este saber es construido, nos enfocamos en caracterizar las representaciones que circularon sobre los indígenas en un corpus de artículos especializados que se publicaron en dicho periodo, con el objetivo de identificar las estructuras de sentido a partir de las cuales se pudieran delinear variantes o modelos de representación de la alteridad. A partir de este análisis hemos definido cuatro formas prototípicas de representación, que se desprenden de la identificación de esquemas argumentales a partir de los cuales se construye al "otro" como objeto del mundo en la diferencia más o menos lejana con un "nosotros", se proyectan estilos de relaciones y se establece el potencial aporte de los "otros" al proyecto nacional.
\end{abstract}

Palabras claves: modelos de representación, alteridad, discurso científico-erudito, publicaciones científicas.

In this article, which is linked to two research projects, we identify the representations of otherness present in the scientific/scholarly discourse on the indigenous population in Chile during the first three decades of the twentieth century. This period sees the institutionalization of a science referred to the study of indigenous peoples in Chile (material culture, anthropometry, customs and language), which manifests itself in the foundation of museums, scientific societies and the creation of specialized journals. Along with describing some aspects that refer to the material and social conditions from which this knowledge is constructed, we focus on characterizing the representations of the natives that circulated in a corpus of specialized articles that were published in this period, in order to identify the structures of meaning from which variants or models of representation of the otherness can be derived. In this analysis we have defined four prototypical forms of representation, which emerge from the identification of argumentation patterns from which "the other" is constructed as an object of the world, being different and more or less distant from "us", we outline types of relationship and we establish the potential contribution of the indigenous "others" to a national project.

Key words: Models of representation, alterity, scientific/scholarly discourse, scientific publications.

La raza araucana pasa hoy por un periodo de transformación. Lo que nuestra obra refiere acerca de sus costumbres y supersticiones, dentro de poco ya no corresponderá a la realidad ni se guardará memoria de ello; por eso hemos querido conservar estos detalles para la ciencia etnológica; al mismo tiempo creemos que por la lectura de estas páginas nadie se formará un juicio desfavorable de los indios de hoy en día (Augusta y Frauenhäusl 1910:VII).

\footnotetext{
${ }^{1}$ Departamento de Antropología, Núcleo de Estudios Interétnicos e Interculturales, Universidad Católica de Temuco, Termuco, Chile. hectmora@uct.cl

${ }^{2}$ Departamento de Lenguas, Núcleo de Estudios Interétnicos e Interculturales, Universidad Católica de Temuco. Temuco, Chile.gpayas@uct.cl
}

Recibido: enero 2020. Aceptado: mayo 2020.

http://dx.doi.org/10.4067/S0717-73562021005000804. Publicado en línea: 20-junio-2021. 
Como advierten algunos investigadores, existe una tendencia a pensar los museos y otras instituciones científicas como meros dispositivos de propaganda y control de los Estados nacionales, y en tal sentido, como máquinas de representación vinculadas al predominio o consolidación del lado oscuro de la modernidad (Podgorny y Lopes 2013). Es indudable que el contexto histórico-social condiciona y modula el discurso social y científico sobre la nación y el "otro" indígena, sosteniéndose en la articulación de la colonialidad del saber y el ser mediante mecanismos lingüísticos con los que se produce la diferencia y clasificación de los "sujetos" (Maldonado-Torres 2007) ${ }^{1}$. Asimismo, es indiscutible que este discurso fue elaborado por una élite letrada mayoritariamente blanca y masculina que inscribió al "otro" indígena y le "... asignó un lugar, un perfil y un papel en la galería de los componentes de la nación..." (Segato 2007:31). Sin embargo, sería poco acertado insistir en que todo discurso social, científico y/o antropológico tuvo como fin último generar un saber dirigido a justificar y sustentar un sistema colonial de corte imperial o republicano (Asad 1973). Este lugar común en las interpretaciones históricas requiere ser examinado, invocando el principio relativista y crítico que la misma antropología buscó situar en su base epistemológica. Las "formaciones nacionales de la alteridad" (Segato 2007:29) no debiesen ser clausuradas y definidas como constructos unívocos y reproductores de representaciones estereotípicas y discriminatorias, sobre las cuales se legitima el proyecto civilizatorio nacional. Conviene, antes bien, explorarlas, recogiendo la complejidad que cruza la formación de estos discursos históricamente situados, y disponernos a una apertura que acoja las disputas y tensiones en torno al ideario de la nación y las representaciones de los indígenas que se ponen en juego desde distintos lugares, conforme a las posiciones de los locutores, la identificación de los destinatarios, los argumentos puestos en escena y la finalidad que estos persiguen (Maingueneau 1980).

En este artículo se exponen los resultados de investigación de dos proyectos que analizaron el discurso erudito referido al sujeto indígena entre 1900 y 1930, con el objetivo de caracterizar las representaciones que se construyen y a partir de ello, identificar modelos de alteridad que circularon en esa época. Por modelo entendemos un sistema de sentido que actúa como estructura interpretativa organizadora de los objetos o de los conceptos (dotada de características que se justifican a nivel argumentativo), que es común o compartido por un colectivo, y que puede diferenciarse de otros sistemas de sentido operantes en un mismo momento en otras comunidades o grupos (Grize 1993; Hiernaux 1995). En este marco, la alteridad puede ser pensada como una construcción modelada de la diferencia cultural, es decir como una representación esquematizada que organiza y justifica el conjunto de características a partir de las cuales definimos a "los otros" (sobre predicaciones o atribuciones de sentido) y proyectamos un estilo de relación, en función de la distancia (proximidad o lejanía) que establecemos conforme a la cualificación (de orientación positiva o negativa) que adquieren los atributos puestos en escena. A nivel argumentativo, un modelo se presenta como una propuesta genérica inferible en tanto que nutre o modula las esquematizaciones, es decir, imágenes verbales dialógicas, que operan en situaciones particulares -sin validez universal, ya que se ajustan a una situación y/o comunidad de habla-, a través de las cuales un sujeto enunciador moviliza un microuniverso hacia un interlocutor con fines de persuasión (Grize 1993, 2008).

Para laidentificación de los modelos de representación de la alteridad nos hemos basado en un amplio trabajo de archivo, que implicó revisar un número significativo de fuentes (actas de gestión institucional, prensa, correspondencia, notas), que permitieron, además, comprender el contexto social y científico de época (Mora 2016; Mora y Vásquez 2018). Se elaboró un catastro, y se clasificaron y analizaron más de doscientos artículos publicados en revistas científicas de circulación nacional vinculadas al conocimiento de las poblaciones indígenas pasadas y presentes ${ }^{2}$. El análisis permitió distinguir elementos comunes en conexión con el discurso social o doxológico, que pueden ser interpretados como derivaciones de la ideología del progreso en su función de pre-construido cultural (Grize 1985, 1993) y partícipes en la formación nacional de las alteridades. Desde esta base se crea una representación del "otro" indígena en un tiempo/espacio pasado ${ }^{3}$, lo que se articula, por ejemplo, a través de los topoi "integración" y "asignación de nombres". Como indica Plantin (1998), el topos (pl. topoi) refiere a una convención admitida en una comunidad de habla -algo que se da por sentado-, que se entiende como un lugar común en el que se apoya la argumentación y que autoriza ciertas conclusiones. En este sentido, el indígena es visto como aquello que desapareció, desaparece o desaparecerá, y así se construye en una representación que busca definirlo en su especificidad (unas determinadas costumbres, creencias, materialidad, física) desde su condición de miembro de una clase mayor (los indígenas).

Sin embargo, y más allá de la operatoria de este elemento común, pudimos distinguir algunas variantes entre, por una parte, las representaciones sobre las que se fundamentaba la asimilación/desaparición de los indígenas y por otra, las que promovían la conservación de sus formas de vida y costumbres. Observamos así la puesta en escena de distintas formas de alteridad (Briones 1998; Peirano 2008), que escapan a la dualidad clásica nosotros/otros en tanto dos totalidades internamente homogéneas. En este sentido, advertimos perspectivas 
esencialistas que discuten con las de impronta relativista. Estas representan al indígena en su diversidad interna, atribuyéndole distintas características y potencialidades, e incorporándolo en una dinámica que pone énfasis en el contexto en que las relaciones intra e interétnicas tienen lugar. En ellas, el otro indígena no es unívoco, se identifican los distintos grupos, con su heterogeneidad, incluso en aquellos que son considerados como parte de una misma "etnia".

Dicho esto, a partir del análisis se han definido cuatro modelos de alteridad, entendidos como estrategias representacionales con base en esquemas argumentativos (Grize 1985, 1993): dos que tienden a definir lo indígena y fijar sus atributos como inmutables, propios de su ser o estado inferior. Otros dos modelos lo sitúan como producto de las relaciones sociales o contextuales, relevando su capacidad y desarrollo cultural, y destacando los contactos internos como un factor por considerar. Estos cuatro modelos se expresan en diversas formas de organización discursiva, y sus destinatarios son múltiples: gobierno, iglesia, intelectuales, políticos, el ejército y algunos letrados indígenas. A través de las representaciones que articulan, se busca convencer de la "utilidad/inutilidad" de los indígenas conforme a un ideario de nación, y de su posibilidad/imposibilidad de inclusión por mediación de distintas instituciones/ dispositivos (educativas, misionales, castrenses), acentuando o minimizando atributos de capacidad física, intelectual, cultural.

Desde el punto de vista retórico-argumental, también se persigue persuadir o justificar la acción de distintos actores que articulan/construyen su discurso en torno a lo indígena; en tal sentido, los productores de conocimiento científico y antropológico (etnológico, arqueológico, lingüístico, biológico) buscan la legitimación de su quehacer en el espacio público y político. En este caso, la construcción del objeto del discurso (Grize 1985, 1993; Wodak 2003) se produce conforme a normas de la comunidad discursiva, remitiéndose a problemas propios de la antropología (problemas generales y locales), usando su terminología, entablando discusiones teóricas y apuestas metodológicas propias de estos estudios. El saber producido se ancla en el preconstruido cultural o lugar común de la asimilación, idea extendida desde fines del siglo XIX y hasta mediados del XX, indicando que su aporte como ciencia radica en dejar registro de estos grupos antes de su desaparición y aminorar el efecto del progreso sobre ellos.

Esta investigación espera aportar al debate sobre la construcción del saber en ciencias sociales y humanas, analizando los mecanismos y contenidos a partir de los cuales se legitima el conocimiento/objeto en su vinculación con ciertos contextos y actores fuera del espacio de la ciencia. Exponemos algunos enfoques y estrategias que permiten discutir algunas visiones monolíticas o maniqueas que se suelen proyectar sobre la antropología en una etapa particular de la historia. En términos globales, puede ser de utilidad para una reflexión sobre las formas a partir de las cuales nuestra sociedad construye o fabrica las otredades culturales. Anima a una discusión relativa a la naturalización de la realidad, particularmente de ciertas prácticas, y nos emplaza a relevar el papel que juega el análisis de la producción histórica para rastrear cómo estas prácticas son instituidas. Somos sujetos de nuestro tiempo, lo que implica que la interpretación del pasado necesita la comprensión del contexto histórico, relativizando una visión presentista y evitando introducir juicios de valor respecto a las formas de hacer ciencia en contextos distantes en tiempo/espacio.

\section{El Lugar de las Representaciones: Agencias y Construcción del Saber en la Producción Textual Referida a los Sujetos Indígenas}

La producción y comunicación de conocimiento científico/erudito sobre la población indígena en Chile se inicia hacia la segunda mitad del siglo XIX. Destacan una serie de trabajos, organizados principalmente en función de tópicos específicos, como son los estudios craneométricos, sobre materialidad cultural, costumbres y lengua, entre otros (Brand 1941; Gundermann y González 2009; Mora 2016; Porter 1906). En una etapa inicial, que podemos situar entre 1860 y 1910 , este saber se canaliza a través de notas en periódicos, libros y revistas misceláneas como Anales de la Universidad de Chile (1843), la Revista de Santiago (1848-1855) y la Revista Chilena (1875-1880), así como en publicaciones científicas que pueden situarse en la línea de las ciencias naturales, como la revista del Museo de Historia Natural (1842), de la Sociedad Científica Alemana (1885-1936), de la Sociedad Chilena de Historia Natural (1897-1963), las Actas de la Sociedad Científica de Chile (1891-1956), los Anales de la Academia Chilena de Ciencias Naturales (1926-1968), y el Boletín de la Sociedad Biológica de Concepción (1927-1958) (Mora 2016) ${ }^{4}$. En la primera década del siglo XX, y con la creación del Museo de Etnología y Antropología (1912-1928), de la Sociedad de Folklore Chileno (1909-1913), y la Sociedad Chilena de Historia y Geografía (1911), el saber antropológico, en su condición de saber experto, encuentra un lugar más allá de la difusión de conocimientos a través del texto. Con la constitución de un espacio de sociabilidad científica al alero de estas instituciones especializadas ${ }^{5}$, se hace posible la presentación y discusión de distintos trabajos en el marco de las temáticas de interés en el periodo (Mora y Vásquez 2018).

El análisis ha permitido discernir cuatro núcleos temáticos que articulan el quehacer de la antropología desarrollada en Chile en la época de estudio: (a) el origen de la población indígena del país, (b) el grado de contacto 
con otras poblaciones, particularmente del área sur del Perú (Incas o Chibchas) y de otras zonas de América del Sur (pampa argentina), (c) el nivel de desarrollo alcanzado por las poblaciones "aborígenes" de Chile, (d) la particularidad de las poblaciones en cuanto a su cultura material, conformación física, creencias y costumbres.

Estos núcleos temáticos se abordan desde diferentes áreas de estudio, y pueden sintetizarse de la siguiente manera.

\section{1. Área de Etnología y Etnografía}

Concentra casi el $40 \%$ de las publicaciones. Se compone de estudios descriptivos sobre costumbres, creencias, organización social y materialidad indígena (colecciones etnográficas) y estudios comparativos, buscando establecer relaciones entre las poblaciones a través de las prácticas culturales que subsisten. $\mathrm{La}$ investigación se centra en los denominados Araucanos (habitantes de la frontera de Arauco), Fueguinos (habitantes de Tierra del Fuego) y Pascuences (habitantes de Isla de Pascua), estrategia metonímica impuesta por la sociedad nacional y que implicó la denominación del grupo por el lugar, población indígena en su mayoría localizada en la zona sur y sur austral del país. Metodológicamente se procede a través del análisis de fuentes secundarias (archivo/crónicas) y entrevistas. En cuanto a trabajo de campo, se realizan incursiones de días y hasta semanas, y son una excepción las "expediciones" como la llevada a cabo por Gusinde a Tierra del Fuego (tres expediciones al extremo sur), Leotardo Matus en La Araucanía (cerca de un mes), Tomás Guevara (salidas varias a las inmediaciones de Temuco), y Manuel Manquilef. También destaca el aporte realizado desde el terreno mismo por los misioneros capuchinos bávaros en La Araucanía, que son trabajos "descriptivos" sobre temáticas específicas (educación, costumbres, organización, vida material), y que incluyen transcripciones y traducciones de descripciones, cuentos y canciones. Sus principales exponentes son Félix K. de Augusta, Ernesto W. de Mösbach y Jerónimo de Amberga.

\section{2. Área de Prehistoria y Arqueología}

Registra algo más del 30\% de las publicaciones. Se trata de estudios descriptivos de objetos líticos, cerámicos, maderas, rupestres, textiles y metalúrgicos, reunidos en trabajos de excavación, que estaban en colecciones privadas o almacenados en museos (como colecciones privadas donadas a museos destacan las de José Toribio Medina, Augusto Capdeville, Aureliano Oyarzún, Leotardo Matus, Ramón Barros Grez, Diego Barros Arana y Tomás Guevara). Desde el punto de vista teórico, se observa un esfuerzo por construir una cronología que permita comprender/explicar la prehistoria de Chile, incorporando como elemento central la idea de contacto entre poblaciones o grupos del áreas de Perú (Chibchas-
Incas), así como definir la particularidad y nivel de desarrollo de grupos prehistóricos como los Changos, Atacameños, Chalingas, indígenas de Tal-Tal, entre otros. Sus autores principales son Max Uhle, Ricardo Latcham, Augusto Capdeville, Aureliano Oyarzún, Roberto Rengifo, Alejandro Cañas Pinochet, Gualterio Looser, Arturo Fontecilla y Francisco Cornely. El trabajo arqueológico se centra en la zona norte, y en menor medida en la zona sur (Araucanía), y consiste en la descripción de objetos como alfarería y en la realización de excavaciones; destaca en ello Dillman Bullock.

\section{3. Área de Lingüística indígena}

Registra cerca del 6\% de las publicaciones. Si bien en las otras áreas no puede dejar de mencionarse con frecuencia la lengua, los estudios lingüísticos constituyen una especialidad en sí, con un número reducido de autores reconocidos como expertos por los demás estudiosos. Estos autores pretendieron actualizar, siguiendo métodos de la lingüística moderna, el conocimiento producido por los misioneros gramáticos del periodo Colonial. Su producción se compone de investigaciones gramaticales y lexicográficas, principalmente de la lengua mapuche y sus variantes dialectales, pero, sobre todo de transcripciones de relatos, cantos, diálogos (de mayor o menor extensión) traducidos y explicados. Esta labor de compilación y transcripción sirvió para ejemplificar los usos de la lengua y, a la vez, para rescatar la producción literaria del pueblo mapuche. La figura más influyente es la del filólogo alemán Rodolfo Lenz, que irradia sobre los trabajos de los misioneros Félix de Augusta y Ernesto W. de Mösbach y sirve de referente para todos los interesados en materia lingüística, folklore y etnografía. Otros estudiosos son Manuel Manquilef, Tomás Guevara, Rodolfo Schuller, Alejandro Cañas Pinochet (para la lengua veliche), Fray Pedro Armengol Valenzuela (para el araucano y habla popular de Chiloé) y Francisco San Román (para el kunza). Estos trabajos fueron hechos en colaboración con hablantes indígenas (por ejemplo Domingo Huenuñanco, Juan Amasa, Lorenzo Coliman), algunos de los cuales (como Manuel Manquilef y Segundo "Calvun" Jara) publicaron obra propia. Respecto a las demás lenguas indígenas, no constituyen objeto de estudio debido a la creencia de que sus hablantes habían desaparecido. Después de los años 1930 se publican otros trabajos descriptivos y de traducción, destacando los de Sebastián Englert (Mapuche y Rapa Nui), Martín Gusinde (Selk'nam) y Grete Mostny (Mapuche).

\section{4. Área de Antropología Física}

En su mayoría estudios descriptivos y comparativos de tipo craneométrico y antropométrico, componen el 
4\% del corpus. Es hacia fines de los años 1930 cuando se desarrollan estos trabajos de orientación fisiológica (principalmente adscritos a la Sociedad Biológica de Concepción), dado el interés que las poblaciones indígenas generan en médicos, en particular los llegados de Europa. Algunos estudios aportan datos para fundamentar la diferencia indígena/no indígena o sostener la igualdad e incluso superioridad de la capacidad física de los primeros. También tuvieron por objeto aportar pruebas para establecer la distinción entre las distintas razas indígenas, o evidenciar su nivel de contacto. Destacan a este respecto los trabajos de Luis Vergara Flores (1902, 1904), Karl Henckel (1933), Leotardo Matus (1912) y Ricardo Latcham (1912).

Desde la perspectiva que nos ofrece la posibilidad de ver en conjunto esta producción de 30 años, podemos decir que, de las distintas tesis que se plantean, la central, que articula las interpretaciones que emanan de las investigaciones en las distintas áreas, distingue entre unos argumentos que indican una fuerte influencia de las creencias y cultura material de la población del norte (andes centrales y sur del Perú en distintos periodos) sobre las poblaciones del sur, y otros, que sostienen en cambio una influencia relativa, reducida a algunos aspectos de la materialidad. También tuvo importancia el planteamiento de Latcham (1912) en torno al contacto de poblaciones del área pampeana, que se establecen en la frontera y que asimilan o expulsan a la población preexistente. Desde el punto de vista teórico, resulta significativa la categoría de contacto cultural, que articula las tesis antes mencionadas y que postula la influencia de poblaciones más adelantadas provenientes del área norte sobre el sur del país.

Por otro lado, frente a visiones evolucionistas nutridas por autores franceses (Guevara 1917), se destaca en estos estudios la importancia de la dimensión histórica, así como las propuestas que sostienen una visión relativista de la evolución de los grupos, cercana a la concepción multilineal. Los elementos de prueba o datos distinguen entre aspectos físico-morfológicos (antropometría), lengua (préstamos, topónimos, variaciones), creencias religiosas (algunos elementos de la cosmovisión) y aspectos tecnológicos-materiales (objetos, formas, estilos). La idea de la diversidad cultural intraétnica es sostenida sobre todo por Ricardo Latcham $(1912,1924)$, indicando, por ejemplo, que lo mapuche es el resultado de la influencia de grupos diferentes y que su carácter racial resulta una prueba concluyente.

El trabajo de campo y la investigación etnográfica con base en el canon moderno (Marcus y Cushman 1982) no es predominante (la idea de trabajo de campo intensivo, observación directa y aproximación holística y monográfica), cuestión que se explica por las limitantes económicas y la falta de espacios destinados a la investigación profesional (Mora 2016). Sin embargo, la dimensión empírica y el dominio de la lengua aparecen como aspectos que legitiman las prácticas científicas y se utilizan como credenciales, en particular, en los debates sobre los Araucanos y los Fueguinos (Guevara 1918; Gusinde 1924; Latcham 1924). Desde el punto de vista metodológico, autores como Lenz (1909) le otorgan al folklore la función de recolectar y describir -equiparable a la etnografía-, para así proveer el dato empírico para el trabajo etnológico.

\section{Las Estructuras de Sentido Contenidas en el Discurso Científico sobre el Sujeto Indígena en los Artículos de Orientación Antropológica}

Tanto el origen como el desarrollo de la antropología -al igual que en los estudios del folklore- se entienden en el marco de un discurso histórico social promovido desde las élites europeas (Angenot 2010), el cual establece su hegemonía entre fines del siglo XVIII y mediados del siglo XX tanto en Europa como América (Elias 1987; Nisbet 1998) y que sitúa la idea de progreso como ley natural del desarrollo humano y social. Progreso puede ser entendido como un pre-construido cultural (Grize 1985, 1993, 2008); se acepta como acontecimiento natural la desaparición o reemplazo de lo antiguo (más simple, menos complejo) por lo nuevo (menos simple, más complejo), principio aplicable a cualquier tipo de relación establecida entre distintas clases de objetos, representado la transición en un continuo que implica dos polaridades: $(-) \mathrm{A} \longrightarrow(+) \mathrm{B}$. Adquiere un carácter dóxico, funcionando como el gran argumento que dota de sentido y justifica, por un lado, acciones que promueven la aceleración del proceso de asimilación social o incorporación técnica con la intención, por ejemplo, de fundar un proyecto nacional moderno y barrer toda estructura arcaica o pasada, o llevar el progreso a toda la sociedad; por otro, promueve prácticas de conservación o preservación de lo que desaparece, ya sea con afanes humanistas (dejar inscripción de la diversidad humana) o identitario-nacionalistas (fijar lo que nos une y nos distingue de otros).

En este marco, las ciencias antropológicas aparecen en escena con un discurso que las sitúa como ciencia moderna $\mathrm{y}$, al mismo tiempo, como las encargadas de responder a preguntas ligadas al origen y explicación de la diversidad humana, proponiendo registrar las costumbres, creencias y materialidad de las sociedades que desaparecen. Rescatar y dejar registro del pasado (arqueología) y el presente (etnografía, folklore, etnología), sirven como fundamento de esta perspectiva que reconocemos como decimonónica (colecciones en museos, libros, artículos, fotografías, cilindros de cera se presentan como formas de objetivación de la vida y costumbre de los pueblos primitivos) y lugar desde donde la antropología adquiere su carácter deontológico.

En este marco, se han podido identificar algunos topoi que son transversales en el discurso de la antropología a 
nivel global y en el pensamiento social "occidental", y que se articulan desde el pre-construido antes descrito:

(a) El topos de la asimilación, que indica que frente a la interacción entre dos entidades consideradas con niveles distintos de desarrollo, persistirá aquella definida como más desarrollada o más compleja. Ello permite prescribir que el progreso lleva al inevitable o natural reemplazo de lo que figura en un estado natural (barbarie) por lo civilizado (cultura), desplegando conexiones de causalidad, finalidad, comparación o analogía;

(b) el topos de la definición e interpretación de nombres como diferencia, que implica el acto de designar un grupo social o sujeto en tanto miembro de una clase/cultura y/o constituir objetos anclados en un pre-construido cultural (Grize 1993). Es lo que Wodak (2003) explica como estrategia de referencia, que se orienta a la construcción de grupos internos y externos: “... si una acción, una cosa o una persona (o grupo de personas) recibe el nombre o es designado (como) X, la acción, la cosa, la persona (o el grupo de personas) posee o debería poseer las cualidades, los rasgos o los atributos contenidos en el significado (literal) de X" (Wodak 2003:116-117). La asignación de características actúa como predicación, entendida como atribuciones estereotípicas y valorativas de rasgos positivos o negativos, que operan en el plano argumentativo. El topos de la definición permite nominar, comparar, localizar y clasificar, recurriendo a operaciones, por ejemplo, metafóricas o metonímicas. En este sentido los pueblos o grupos pueden ser clasificados desde una práctica disciplinaria como extinguidos (arqueología)/por extinguirse (etnografía); como designación específica del objeto indígena: chibchaatacameño (desaparecido)/araucano (por desaparecer); como categoría genérica que nombra al objeto: indio, aborigen (araucano, chango, atacameño) $=$ pasado.

En este marco se pone en escena lo que Fabian (1983) define como alocronismo (allochronism), es decir que se recurre a los cronotopos (tiempo/espacio) para sacar del presente al "objeto de estudio", y ello mediante procedimientos discursivos, como la deixis, que puede producir efectos de distanciamiento/diferencia. El uso de categorías como "primitivo", "salvaje", "indio", "araucano" representan la construcción de esa diferencia espacio/temporal y, al mismo tiempo, se interpretan como "supervivencias", en tanto expresión de la persistencia o vestigio de manifestaciones pasadas que desaparecerán por el curso natural del progreso o por la integración civilizatoria.

La cuestión del progreso como adelanto cultural también opera para explicar la consecuencia en la relación entre grupos indígenas, recurriendo a la misma estructura descrita. Para dar cuenta del estado de las poblaciones conforme ciertos adelantos culturales, fue típico recurrir a la situación de contacto con la población del Perú o Inca (de mayor desarrollo): (+) Norte-Inca-Civilizado/ (-) Sur-Araucano-Primitivo. El nivel de primitivismo estuvo vinculado a la ubicación de las poblaciones en el espacio; mientras más al sur, más distancia, menos civilización (p.ej., lo que opera para calificar y clasificar a los denominados Fueguinos).

Hemos identificado, además, construcciones de alteridad que, si bien comparten los aspectos mencionados, resultan más complejas o variadas de lo que se suele afirmar desde la antropología en Chile. En este sentido, la dicotomía clásica "nosotros/ otros", compuesta por dos categorías internamente homogéneas, se complejiza en estos estudios, ya que expresa posibilidades de una diversidad interna. Respecto al "nosotros", se puede visualizar la construcción de la "alteridad en contacto" (Peirano 2008), representada por la categoría de "bajo pueblo" (Lenz 1909). De esta manera, el "bajo pueblo" se constituye en objeto de estudio del folklore entendido como la ciencia del pueblo. Autores como Lenz, por ejemplo, exploran la influencia de la población araucana en la lengua del "bajo pueblo" chileno, identificando supuestas interferencias de la lengua indígena en el habla popular. El bajo pueblo sería, entonces, un "otro". En tanto Guevara (1917) dedica un pequeño acápite referido a la psicología del "roto".

También, y en asociación al tópico "denuncia" (alegato de carácter político que se produce en el contexto de conferencias públicas), se observa la construcción de un "otro" chileno (pluralizado) referido como "personas pudientes", "hombres ricos", "grandes electores", asociados a la usurpación y vulneración de los derechos de la población mapuche, sobre todo en los textos de los misioneros capuchinos bávaros y de investigadores como Leotardo Matus (1912). A estos "hombres ricos" se les atribuyen tanto los efectos negativos sobre condiciones materiales (robo de tierra, quema de siembras) y psicológicas de los araucanos (por ejemplo, la desconfianza y baja motivación al trabajo). En tal sentido, el mapuche es un sujeto producido por las condiciones sociales, económicas y políticas propias del contacto (p.ej., la llamada Pacificación de La Araucanía).

Respecto a la representación de la "alteridad radical" (Peirano 2008), se observan construcciones que establecen diferenciaciones internas (heterogeneidad) que permiten afirmar la diversidad de estas poblaciones -un "otro" diferente y diverso. Esta construcción toma como base el estudio de la prehistoria de Chile, destacando como elementos de prueba los etnónimos (Picunche, Huilliche, Pehuenche, Mapuche), así como variaciones en la lengua y la materialidad. La no homogeneidad del "otro" también se sostiene en la diferenciación anatómica y en la cultura material. Al mismo tiempo, se constata la emergencia de un elemento diferenciador, que distingue entre un "indígena puro" y un "indígena civilizado" y que se construye en el eje temporal (antes:guerrero-puro/ ahora:borracho-impuro) y espacial (cerca de la ciudad/ lejos de la ciudad). Lo puro se encuentra alejado de la civilización, y permite mantener las características 
esenciales de la raza (Matus 1912). En relación a las valoraciones, se aprecia la utilización de adjetivaciones positivas en la representación del "otro" indígena, sobre todo desde el punto de vista moral, intelectual y físico. En este caso lo civilizado esencializado no aparece necesariamente asociado a una carga positiva, ya que implica la pérdida de la singularidad o de los rasgos propios (Amberga 1913, 1917).

\section{Estrategias Representacionales: las Estructuras Argumentativas y Recursos Retórico-Escriturales}

La argumentación se comprende como un procedimiento lingüístico natural cuya finalidad es convencer y persuadir a un auditorio o destinatario (Anscombre y Ducrot 1988; Grize 2008; Vignaux 1976; Wodak 2003). Para Grize (1985, 1993, 2008), toda argumentación procede de un pre-construido cultural, referente que genera el anclaje discursivo, y con el cual se construye sentido. Es resultado de la producción de enunciados interrelacionados conforme a operaciones lógicas con función esquemática, extra e intra-discursivas, que responden a la intencionalidad de quien produce el discurso. En particular, nuestro análisis se centró en aquellas operaciones destinadas a identificar y localizar los objetos de los cuales trata el discurso, reconociendo que cada texto analizado realiza un movimiento dirigido a proporcionar una imagen del indígena (especificación, aserción/determinación y conexión), por referencia a su lengua, su producción cultural, sus costumbres o su conformación biológica.

Conforme a estas operaciones analíticas llevadas a cabo sobre el material, se han identificado cuatro modelos que se vinculan entre sí, compartiendo (la distancia espacial y temporal) o contraponiendo ciertos elementos, que nos permiten concluir que no existe solo una representación del indígena pasado o presente, y por tanto una sola forma de construir el objeto antropológico. Esto puede estar asociado a la dinámica que ha seguido el proceso de institucionalización de la antropología en Chile y, en particular, a la inexistencia de instituciones formativas que hayan regulado o disciplinado las perspectivas teóricas y metodológicas puestas en escena, o también a una delimitación tajante entre ciencia y sociedad, que lleva a la primera a construir un discurso totalmente abstraído de los prejuicios y los estereotipos que circulan en espacio social.

Por otro lado, hay que consignar que los destinatarios del discurso no son solo los miembros de la "comunidad científica" nacional (están, además, los políticos, el gobierno, la iglesia, el ejército y los indígenas letrados). En la búsqueda por legitimar un campo de estudios -convencer de su utilidad -, la estrategia se orienta unas veces a asignar valor positivo al indígena en tanto actor relevante para el proyecto nacional y, en otras, a definirlo negativamente, justificando su asimilación (p.ej., a través de la educación) y promoviendo prácticas anticuarias, de conservación o registro de lo que se consideran vestigios de épocas pasadas.

Puestos en relación, estos modelos pueden ser organizados en función de dos ejes constituidos por cuatro polos con carga valorativas, que han sido seleccionados en tanto dan cuenta de posiciones diversas en las construcciones eruditas: el eje del ser/no ser y el eje tener/no tener y que graficamos en la siguiente estructura cruzada (Figura 1).

El eje del (-) ser/(+)no ser da cuenta de representaciones que fijan o asignan al indígena ciertas características, ya sean propias, inmanentes, consustanciales o adquiridas, cambiantes, mutables. Por ejemplo, la racialización es una expresión del ser esencializado, donde fenotipo, mentalidad y cultura se funden en una amalgama que define el primitivismo, que impide o condiciona la posibilidad de evolución o asimilación del indígena -el cambio solo puede provenir de un estímulo exterior al grupo-, lo que se expresa en autores como Tomás Guevara (1917:411-412):

Toda esta falta de valores psicolójicos, deteniendo el vuelo de su pensamiento, revelan en los araucanos antiguos una intelectualidad esterilizada, que persistió hasta las jeneraciones contemporáneas. La intelijencia araucana, en una palabra, es un campo inculto, pero susceptible de hacerse ferazcomocualquiera otro con los trabajos para ello necesarios... Con una asimilación lenta i bien preparada, esta inteligencia en barbecho de los araucanos de antes i de ahora puede elevarse al nivel de la lójica civilizada. Hai dificultades casi insuperables para llegar a este fin; el proceso de trasformación es por lo menos en estremo lento i complicado (el subrayado es nuestro).

En el otro extremo, es posible situar a autores que resaltan las posibilidades de cambio del indígena a través de la instrucción educativa, las relaciones con su medio ambiente o la interacción con sus contemporáneos sociales, tal como indica Jerónimo de Amberga (1913:20):

El araucano, como adoptó los aperos agrícolas, $\underline{\text { ha }}$ aprendido también las ventajas de la maquinaria agrícola. Conozco indios en el corazón de Araucanía, que poseen máquinas y motores; he visto trabajar a araucanos, semanas enteras, sumergidos en el pantano, acosados por miles de zancudos, para abrir desagües y canales de riego en su terreno (el subrayado es nuestro).

El eje del (+)tener/ (-)no tener se conforma atendiendo a la identificación de características o cualidades positivas 


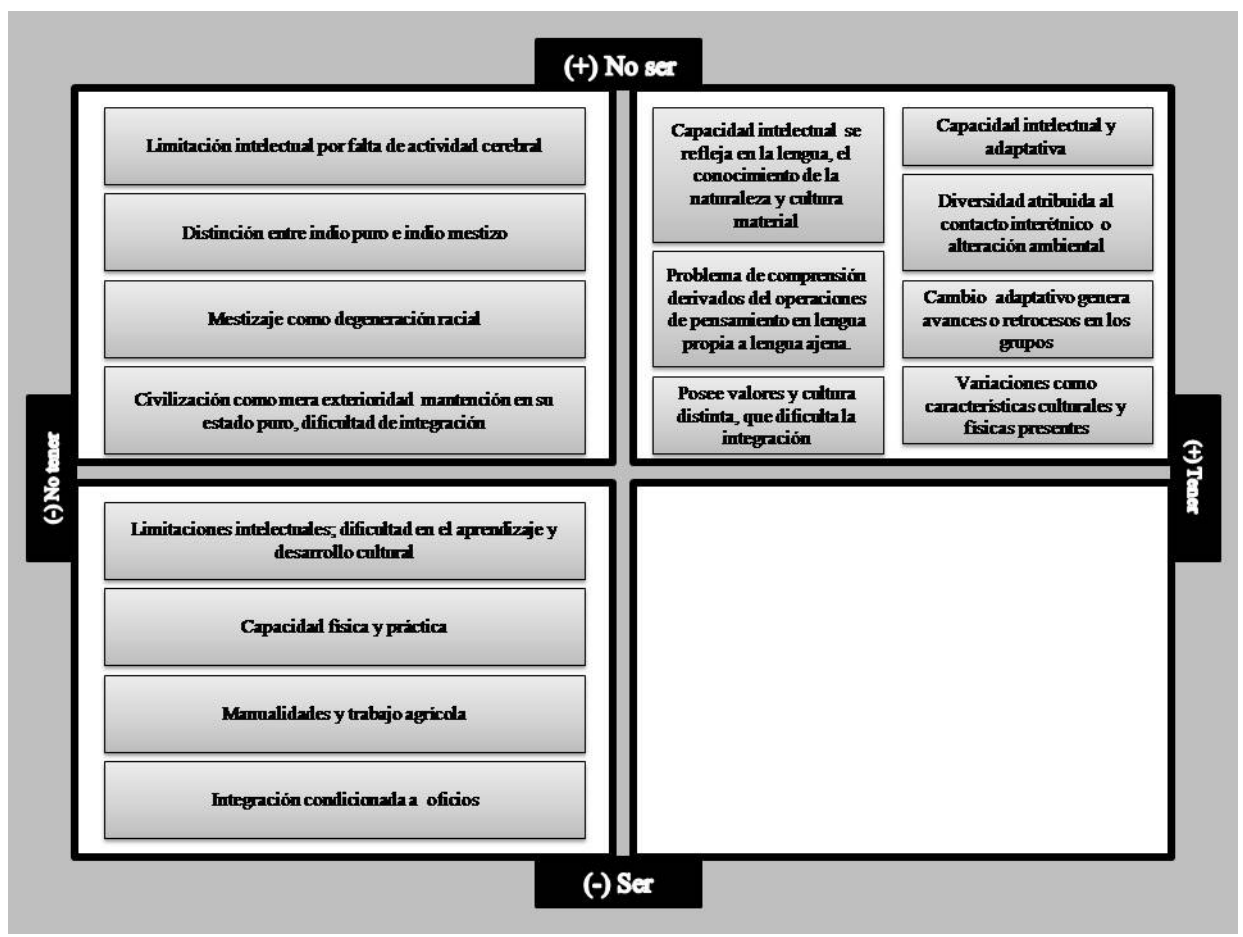

Figura 1. Estructura comparativa de los modelos según ejes definidos.

Comparative structure of the models according to defined axes.

o negativas, asociadas a un estado de desarrollo inferior (primitivo) o superior (civilizado) del indígena -en comparación con el chileno-, reflejo de la capacidad/ incapacidad de raciocinio, abstracción, creatividad, sensibilidad o de complejidad en su cultura material (inteligencia). En el polo "tener" puede ser graficado a partir de la siguiente cita:

Diremos simplemente que los habitantes más antiguoseran afines a los pehuenches; el pueblomás culto a que hemos hecho referencia era semejante a los cuncos; y que los costinos eran probablemente una mezcla de éstos con los mapuches, o tal vez con los pehuenches... Sabemos que este antiguo pueblo practicaba la agricultura en tiempos preincaicos, porque hallamos en las tumbas de esa época los objetos de piedra y de madera destinados a esta industria. La alfarería pintada de los mismos sepulcros demuestra que en ese arte también había avanzado mucho. De igual manera, el hallazgo de objetos y útiles para la fabricación de tejidos, restos de estos mismos y madejas de las lanas usadas, dejan de claro que esta industria también fue conocida en tiempos preincaicos." (Latcham 1912:317-323, el subrayado en nuestro).
En tanto en el polo "no tener", podemos situar a Rodolfo Lenz, para quien:

El mapuche es una lengua que tiene diversos rasgos sumamente curiosos. Hay solo una clase de flexión aglutinada en ella, ... los sustantivos $\mathrm{y}$ adjetivos en si son invariables, no hay declinación ni concordancia. Pero tampoco hay preposiciones... en cambio, no solo los verbos sino también sustantivos, adjetivos y adverbios pueden conjugarse, juntarse con pronombres sujetos aglutinados, ¿cómo se expresa entonces la relación gramatical entre los diferentes complementos del pensamiento, si ni siquiera existen casos complementarios de los pronombres personales? (Lenz 1917:135, el subrayado en nuestro).

En esta estructura el primer modelo se ubica en el cuadrante del ser /no tener, el segundo en el cuadrante del no ser/no tener y los modelos tercero y cuarto en el cuadrante definido por la intersección de los polos no ser/ tener. La diferencia entre estos últimos dos modelos radica en que el primero enfatiza los procesos intelectuales o la dimensión interna que se expresa en el uso de una lengua distinta -castellano-, en tanto el segundo enfatiza el 
factor adaptativo ligado a grandes procesos vinculados a circunstancias externas ambientales o políticas ${ }^{6}$.

Primer modelo: produce una construcción esencialista de un indígena con atributos negativos que se sitúan a nivel psicológico o mental, a partir de la disyunción incapacidad/capacidad. El indígena posee limitaciones intelectuales para realizar operaciones abstractas, y manifiesta más bien una capacidad concreta y práctica (tiempo: un estado anterior de desarrollo). Su rasgo distintivo es la fortaleza física y su aptitud para el trabajo manual. Lo define su apego a la tierra, su armonía con la naturaleza (lugar), que lo vuelve potencialmente un cultivador útil de los campos. Se observa la operatoria de una estructura que define al otro en un estado natural o salvaje: (a) ser (concreto, físico, culturalmente básico), (b) capacidad (práctica), (c) lugar (naturaleza agreste, campo, distante), (d) tiempo (pasado). Capacidad/ incapacidad reflejan la construcción de un argumento cuyo tratamiento de los temas (p.ej., aptitud a la instrucción educativa, capacidad agrícola y militar) permite inferir que los destinatarios del discurso se sitúan en la esfera política, militar y eclesial (el potencial para su integración a la sociedad chilena). Desde este modelo se plantea que el indígena debe permanecer en el campo, su hábitat natural, debido a que la urbe lo deforma (fomenta el alcoholismo, la competencia y el aislamiento). Puede ser útil a la nación gracias a la educación en oficios manuales y agrícolas, y su potencial depende de la instrucción moderna para el cultivo de sus tierras. Es un modelo a partir del cual se construye la diferencia y se promueve la integración, que se justifica atendiendo o relevando la capacidad de los indígenas. Desde esta argumentación el indígena puede ser útil, por ejemplo, al ejército dada su capacidad física y disciplina, y para el desempeño de oficios, desde la óptica productiva.

Segundo modelo: construye un "ser" indígena como diferente en función de su menor capacidad mental, distinguiendo entre un estado puro (naturalezal campo) e impuro (cultura/ciudad). El argumento recurre a la disyunción entre raza buena (pura) y raza mediocre (impura), esta última producto del mestizaje. A través del mestizaje el "ser" indígena se degenera, ya que condensa lo peor de las razas al conjugar lo más negativo de ambas entidades étnicas. En este sentido, el indígena del pasado (extinto) es mejor que el indígena del presente (vivo), al que se le asignan atributos como bebedor, pendenciero, sin capacidad de trabajo, neurópata. Los designados como "indios mestizos" constituyen una nueva categoría, la de indios "instruidos", que se construye en función de la distinción entre lo exterior y lo interior como expresión de la psiquis y el cuerpo. El indígena instruido toma la exterioridad y forma de la civilización (vestimenta o una estética), pero internamente alberga una serie de atributos negativos: agresivo en las palabras, odio hacia la otra raza, violento, naturalmente rudo y arrogante, sin razonamiento superior. Esto implica que la civilización del indígena solo se expresa a nivel exterior (ser/parecer), lo cual puede modificarse a partir del ejercicio del raciocinio, por ejemplo, por medio de la educación. El problema mental del indio no radica tanto en un defecto biológico de su cerebro, sino en la falta de actividad intelectual y su atrofia.

Tercer modelo: asume un carácter relativista. Afirma que la diferencia entre indígena/no indígena no se articula desde la idea de raza inferior/raza superior; concluye que no hay razas superiores ni inferiores, sino diferentes marchas en la historia. Ello implica una discusión con las tesis evolucionistas unilineales y con los esencialismos, ya que el indígena no "es", sino que se constituye en función de distintos contextos/ circunstancias. La igualdad en la diferencia se funda en el estudio de la lengua como expresión de desarrollo intelectual; se observa una complejidad lingüística -como expresión de la mente- a la cual se asignan atributos positivos como: idioma perfecto e interesante, características gramaticales y sintácticas que reflejan trabajo intelectual, léxico abundante, sobre todo en lo referente a la naturaleza (detalle de sus relatos). El problema de la no comprensión del indígena proviene de la dificultad que entraña el ejercicio mental de tener que pasar de un idioma a otro (de ahí las interferencias). Respecto a su contribución a la nación, se indica que la gran diferencia y el desafío radica en su concepción distinta (cultura) y en la ausencia de noción de propiedad, valor económico y trabajo.

Cuarto modelo: también tiene su base en un argumento relativista. El indígena no refleja un estado único, natural e invariable (unidad biopsíquica y evolución unilineal). Existe diversidad al interior de lo que se define como indígena (moral y cultural), distinguiendo entre un estado estacionario y otro de cambio. El paso de uno a otro genera variaciones en las características culturales del grupo, que se deben a factores externos de tipo ecológico y social. El estado estacionario es propio de grupos aislados (Espacio=lejos) que siguen un progreso natural, que los lleva a mantener una condición primitiva, lo que se debe a las condiciones de su entorno (abundancia/escasez) y aislamiento (no contacto/ contacto). El cambio implica aparición de factores tales como alteraciones ambientales o contacto entre grupos (p.ej., bélico o por intercambio), que desencadena un impulso adaptativo cuyo efecto es el desarrollo cultural o el retroceso. El contacto también tiene una expresión a nivel biológico, que se observa en la configuración física de los sujetos, particularmente entre los distintos tipos anatómicos. 
Estos modelos se construyen desde una comunidad discursiva especializada, que busca legitimar el conocimiento generado como saber experto en la sociedad (Figura 2). Sin embargo, no existe una forma única de organización textual: hay artículos científicos, notas informativas breves y capítulos de libro (la falta de recursos hizo que se publicaran primero los capítulos en revistas antes de poder compilarlos como libro). Prácticamente en la totalidad de los casos, con independencia de su formación y/o ubicación institucional (funcionario público, educador, empresario, misionero), los autores hablan desde o hacia los estudios científicos, recogiendo los aportes de la etnología, arqueología, folklore, y desplegando el uso de terminología especializada (conceptos teóricos y metodológicos, operaciones y procedimientos técnicos). En el nivel enunciativo, cabe señalar la presencia del discurso referido (la heterogeneidad o intertextualidad en la configuración de los enunciados) por medio de citas, sea de otros textos especializados, fuentes archivísticas, registros estatales, informes institucionales, o informes o relatos de sujetos indígenas (creándose así textos heterolingües, que incluyen vocablos indígenas, discurso referido indirecto o reproducción de textos orales traducidos).

\section{Comentario Final}

Si partimos del supuesto que el texto que canaliza el saber erudito y/o científico, como cualquier otro producto cultural, es tanto un artefacto de convención como un artilugio (Atkinson 1990, Clifford 1983, Fabian 1983; Geertz 1989; Marcus y Cushman 1982), se vuelve imperativo analizar los mecanismos y recursos semiolingüísticos que se ponen en juego a la hora de representar o fabricar la "alteridad cultural" (Briones 1998; Fabian 1983; Peirano 2008; Sturge 2007). Junto con profundizar en los antecedentes relativos al contexto histórico-social en el cual acontecen las posibilidades expresivas (Clifford 1983), hemos seguido los lineamientos que exploran la producción intelectual a nivel argumentativo y analizado las modalidades y recursos que caracterizan las representaciones puestas en juego desde una comunidad discursiva finisecular (Grize 1985, 1993; Maingueneau 1980). Poniendo acento en la forma, contenido y justificación de las interpretaciones/argumentos que se ponen en juego (pre-construido, referente, pregunta, operación lógico-discursiva), postulamos que estas representaciones pueden ser entendidas como modelos prototípicos que modulan los discursos circulantes en las distintas escenas -eruditos, políticos, religiosa-, y que en determinados casos constituyen y son constituidos desde la doxa social.

La hipótesis inicial propuesta implicó el desafío de poner en tela de juicio un lugar común: que el saber erudito y/o científico -pensado como totalidad homogéneafue constitutivo o legitimó la política asimilacionista desplegada por el Estado-Nación chileno, al fundarse sobre un discurso cuyo tema era la inferiorización de las culturas indígenas. Nuestra estrategia de investigación,

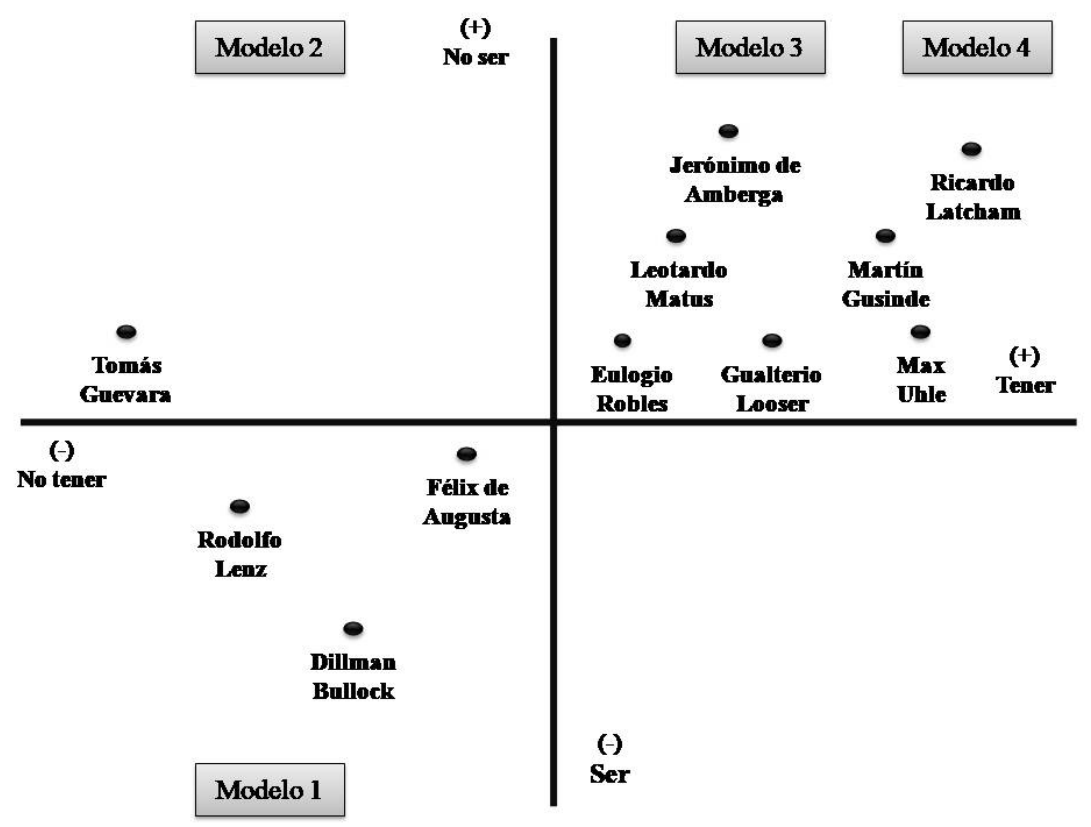

Figura 2. Posicionamiento de los actores según los modelos de alteridad ${ }^{9}$.

Positioning of the actors according to the alterity models. 
partiendo de los distintos discursos que sitúan como locus la ciencia y/o el saber erudito, y animada por los aportes de los análisis del discurso (Grize 1985, 1993; Maingueneau 1980; Sturge 2007; Wodak 2003), permite abrir una perspectiva fructífera que relativiza estos puntos de vista, y pone de relieve la diversidad de formas que adquiere la construcción de la alteridad en Chile.

Si bien el saber antropológico no gozaba de plena legitimidad en el espacio social nacional (Gusinde 1916) ${ }^{7}$, es decir, se consideraba como un conocimiento de poca relevancia y escasa utilidad (Mora y Vásquez 2018), pone de manifiesto cierto grado de poder que Peirano (2008) identifica como uno de los "pecados" de la antropología, y que podemos hacer extensivo a la construcción de un objeto de conocimiento subalternizado (MaldonadoTorres 2007), ello a partir de la articulación entre raza/fenotipo y cultura/psiquis. De esta manera, se desemboca en la fabricación de un objeto exotizado a través de la distancia física, cultural y geográfica, y que se expresa en la puesta en escena, por ejemplo, de los alocronismos (Fabian 1983) o de operaciones lógicodiscursivas orientadas a construir una determinada representación (Grize 1985, 1993). Sin embargo, la radicalidad contenida en las representaciones sobre los indígenas varía, fracturando la imagen homogénea con la cual se suelen interpretar las construcciones científicas o eruditas a la manera de lo que Laclau y Mouffe (1987) han denominado estrategia contra-hegemónica por oposición $^{8}$; al mismo tiempo, el supuesto del aislado cultural, soporte de la visión autocontenida con la que se suele caracterizar a las culturas o pueblos indígenas pierde pie, cada vez que distintos autores aportan antecedentes del contacto, intercambio y transformación de las poblaciones desde época prehispánicas. En una época en la que el conocimiento antropológico pugna por su inscripción formal, y en un contexto nacional cruzado por la fricción interétnica (Cardoso de Oliveira 1963), a poco tiempo de la implantación de un sistema reduccional (Mora y Samaniego 2018), el espacio intelectual muestra su heterogeneidad, expresando tensiones que emergen en los debates sobre el origen y características que definen a la población indígena en Chile, lo que ha sido puesto en evidencia por otras investigaciones (Crow 2013; Gundermann y González 2009; Mora y Vásquez 2018; Pavez 2015). La puesta en común de ciertos supuestos de época, que actúan como pre-construidos culturales, no impide que distintos modelos de representación entren en juego, y que desde el conocimiento experto alimenten o discutan el lugar que la sociedad y materialidad indígena ocupan en la nación. La diferencia entre los planteamientos, por ejemplo, de Tomás Guevara (Modelo 2) y los presentados por Ricardo Latcham (Modelo 4) o Jerónimo de Amberga (Modelo 3), no son solo debates teóricos de la antropología o etnología, sino también confrontaciones entre formas de representar la alteridad indígena y de inscribirla en el imaginario de la nación (Figura 2).

Dicho esto, y como se indicó en la introducción, las formaciones nacionales de alteridad, más que expresión de una matriz única de generación de formas de alteridad o constituir una unidad de sentido que nutre las representaciones hegemónicas de la nación (Segato 2007), debiesen ser pensadas como un campo de disputa/ debate de representaciones (Laclau y Mouffe 1987), que acontecen y que se orientan tanto hacia una comunidad especializada como hacia los distintos actores políticos. El contexto histórico de emergencia y las condiciones de producción de un saber erudito o científico, así como los diversos modelos de alteridad identificados, abren una ruta para explorar la heterogeneidad de los discursos a partir de los cuales históricamente se ha buscado definir a los otros, y al mismo tiempo se convierten en oportunidad para reconocer cómo estas formas se transmiten y reproducen en distintos contextos en el presente.

Agradecimientos: Agradecemos al Fondo Nacional de Investigación Científica y Tecnológica, que a través del financiamiento de los proyectos Fondecyt Iniciación 11170461 y Fondecyt Regular 1170419, han hecho posible nuestras investigaciones. Del mismo modo, agradecemos al Centro de Estudios Latinoamericanos (Zilas) de la Universidad Católica de Eichstätt, Alemania, que en el marco de la estancia de investigación de uno de los autores del artículo, permitió la presentación de parte de los resultados aquí expuestos; en particular al Dr. Thomas Fischer, la Dra. Roswitha Kramer y la doctorante Christiane Hoth. También agradecemos a la Dra. Danielle Zaslavsky (Colegio de México) y a la Dra. Hebe Vessuri, cuyos aportes han nutrido nuestro enfoque y reflexiones. Por último, a los pares evaluadores, cuyos comentarios han contribuido sin duda a mejorar este trabajo.

\section{Referencias Citadas}

Amberga, J. 1913. Estado intelectual, moral y económico de los araucanos. Revista Chilena de Historia y Geografía VII (11):5-37.

Amberga, J. 1917. Agricultura Araucana. Revista Chilena de Historia y Geografía XXI (25):54-80.

Angenot, M. 2010. El Discurso Social. Los límites Históricos de lo Pensable y lo Decible. Siglo XXI, Buenos Aires.
Anscombre, J.C. y O. Ducrot 1988. La Argumentación en la Lengua. Gredos, Madrid.

Asad, T. 1973. Introduction. En Anthropology and the Colonial Encounter, editado por T. Asad, pp. 9-19. Ithaca and Humanities Press, London y New Jersey.

Atkinson, P.1990. The Ethographic Imagination. Textual Constructions of Reality. Routledge, London. 
Augusta, F. y S. De Frauenhäusl 1910. Lectura Araucanas. Editorial San Francisco, Padre Las Casas.

Brand, D. 1941. The Status of Anthropology in Chile. New Mexico Anthropologist 5 (3):55-71.

Briones, C. 1998. La Alteridad del Cuarto Mundo. Una Deconstrucción Antropológica de la Diferencia. Ediciones del Sol, Buenos Aires.

Cardoso de Oliveira, R. 1963. Aculturación y "fricción interétnica" América Latina 6 (3):33-46.

Clifford, J. 1983. On Ethnographic Authority. Representations 2:118-146.

Crow, J. 2013. The Mapuche in Modern Chile. A Cultural History. University Press of Florida, Miami.

Elias, N. 1987. El Proceso de la Civilización. Investigaciones Sociogenéticas y Psicogenéticas. Fondo de Cultura Económica, México DF.

Fabian, J. 1983. Time and the Other. How Anthropology Makes its Objects. Columbia University Press, New York.

Geertz, C. 1989. El Antropólogo como Autor. Paidós, Barcelona.

Grize, J. 1985. Los objetos del discurso: conexión y oposición. Discurso, Teoría y Análisis 6 (2):83-91.

Grize, J. 1993. Logique naturelle et représentations sociales. Papers on Social Representations 2 (3):1-9.

Grize, J. 2008. El punto de vista de la lógica natural: demostrar, probar, argumentar. En La Argumentación Hoy, Encuentro entre Perspectivas Teóricas, editado por M. Doury y S. Moirand, pp. 43-53. Ediciones de Intervención Cultural, Madrid.

Guevara, T. 1917. La Mentalidad Araucana. (Continuación). Anales de la Universidad de Chile, Tomo 140 (Ene.-Jun.): 383-418.

Guevara, T. 1918. La etnolojía araucana en el poema de Ercilla (Continuación). Anales de la Universidad de Chile, Tomo 142 (Ene.-Jun.):743-766.

Gundermann, H. y H. González 2009. Sociedades indígenas y conocimiento antropológico. Aymaras y Atacameños de los siglos XIX y XX. Chungara Revista de Antropología Chilena 41 (1):113-164.

Gusinde, M. 1916. El Museo de Etnología y Antropología de Chile. Revista Chilena de Historia y Geografía XIX (23):30-47.

Gusinde, M. 1924. Cuarta expedición a la tierra del fuego Publicaciones del Museo de Etnología y Antropología de Chile IV (1 y 2$): 7-68$.

Henckel, K. 1933. La disposición de las crestas papilares de las falangitas en los idígenas de la provincia de Cautín. Boletín de la Sociedad Biológica de Concepción VII:53-60.

Hiernaux, J. 1995. Analyse structurale de contenus et modèles culturels En Pratiques et Méthodes de Recherche en Sciences Sociales, editado por L. Albarello, F. Digneffe, J. Hiernaux, C. Maroy, D. Ruquoy y P. Saint-Georges, pp. 56-82. Armand Colin, Paris.

Laclau, E. y Ch. Mouffe 1987. Hegemonía y Estrategia Socialista. Fondo de Cultura Económica, Buenos Aires.

Latcham, R. 1912. Elementos indígenas de la raza chilena. Revista Chilena de Historia y Geografía IV (8):303-329.

Latcham, R. 1924. La organización social y las creencias religiosas de los antiguos araucanos. Publicaciones del Museo de Etnología y Antropología de Chile III (1 y 2):245-868.

Lenz, R. 1909. Etnolojía i Folklore. En Programa de la Sociedad de Folklore Chileno, pp. 5-12. Imprenta y Encuadernación Lourdes, Santiago.
Lenz, R. 1917. Un diccionario Araucano. Revista Chilena 2:130-136.

Maldonado-Torres, N. 2007. Sobre la colonialidad del ser: contribuciones al desarrollo de un concepto. En El Giro Decolonial. Reflexiones para una Diversidad Epistémica más allá del Capitalismo Global, editado por S. Castro-Gómez y R. Grosfoguel, pp.127-167. Iesco-Pensar-Siglo del Hombre Editores, Bogotá.

Maingueneau, D. 1980. Introducción a los Métodos de Análisis del Discurso. Hachette, Buenos Aires.

Manquilef, M. 1914. Comentarios del pueblo araucano. La jimnasia nacional (juegos, ejercicios y bailes). Revista de Folklore Chileno IV:94-219.

Marcus, G. y D. Cushman 1982. Ethnographies as texts. Annual Review of Anthropology 11:25-69.

Matus, L. 1912. Vida y costumbre de los indios araucanos. Revista Chilena de Historia y Geografía IV (8):362-410.

Mora, H. 2016. La Institucionalización de las Ciencias Antropológicas en Chile. Una Aproximación a las Dinámicas Socio-Organizativas y Cognoscitivas en la Conformación del Espacio Científico (18601954). Tesis para la obtención del grado de Doctor en Ciencias Sociales, Facultad de Humanidades y Ciencias de la Educación, Universidad Nacional de La Plata, La Plata.

Mora, H. y R. Vásquez 2018. La ciencia y lo "araucano" como ideas fuerza: Antropología y emergencia del "araucanismo" en Chile. En El Pueblo Mapuche en la Pluma de los Araucanistas, editado por H. Mora y M. Samaniego, pp. 22-87. Ocholibros, Santiago.

Mora, H. y M. Samaniego 2018. Introducción. En El Pueblo Mapuche en la Pluma de los Araucanistas, editado por H. Mora y M. Samaniego, pp. 13-21. Ocholibros, Santiago.

Nisbet, R. 1998. Historia de la Idea de Progreso. Gedisa, Barcelona. Orellana, M. 1996. Historia de la Arqueología en Chile. Bravo y Allende Editores, Santiago.

Pavez, J. 2015. Laboratorios Etnográficos. Los Archivos de la Antropología en Chile (1880-1980). Ediciones Universidad Alberto Hurtado, Santiago.

Peirano, M. 2008. Antropología sin culpa: una visión desde Brasil. En Saberes Periféricos. Ensayos sobre la Antropología en América Latina, compilado por C. Degregori y P. Sandoval, pp. 227-247. Instituto de Estudios Peruanos, Lima.

Podgorny, I. y M. López 2013. Trayectorias y desafíos de la historiografía de los museos de historia natural en América del sur. Anais do Museu Paulista: História e Cultura Material 21 (1):15-25.

Porter, C. 1906. Literatura antropolójica y etnolójica de Chile. Revista Chilena de Historia Natural 10 (2):101-127.

Plantin, Ch. 1998. La Argumentación. Ariel, Barcelona.

Segato, R. 2007. La Nación y sus Otros. Raza, Etnicidad, Diversidad Religiosa en Tiempos de Políticas de la Identidad. Prometeo Libros, Buenos Aires.

Sturge, K. 2007. Representing Others. Translation, Ethnography and the Museum. St. Jerome Publishing, Manchester y Nueva York.

Vergara, L. 1902. Estudios comparativos sobre cráneos araucanos y antiguos aimaráes. Revista Chilena de Historia Natural VI(4):197-217.

Vergara, L. 1904. Sobre craneometría y origen de las razas americanas. Revista Chilena de Historia Natural VIII (1-2):16-21.

Vignaux, G. 1976. La Argumentación: Ensayo de Lógica Discursiva. Hachette, Buenos Aires.

Wodak, R. 2003. El enfoque histórico del discurso. En Métodos de Análisis Crítico del Discurso, compilado por R. Wodak y M. Meyer, pp. 101-142. Gedisa, Barcelona. 
Zavala, J. 2018. En busca del ciudadano ideal: fundamentos discursivos de la colonización inmigratoria de La Araucanía durante el siglo XIX.
En El Pueblo Mapuche en la Pluma de los Araucanistas, editado por H. Mora y M. Samaniego, pp. 167-185. Ocholibros, Santiago.

\section{Notas}

${ }^{1}$ Para conocer cómo el concepto de raza apareció en la literatura decimonónica de Chile, y cómo se aplicó para calificar, clasificar y seleccionar distintos grupos europeos en su utilidad para la colonización del sur de Chile, véase Zavala (2018).

${ }^{2}$ El plan de análisis abarcó las siguientes operaciones: lectura de los artículos (material que es trabajado desde el año 2010), clasificación, confección de una tabla de datos, digitalización -mediante sistema OCR-, exploración de textos con asistencia del software dt-Search (Order Date: 11/7/2012; OrderNumber: 16214275223) que permite la segmentación con base en un diccionario de palabras clave, delimitación de las unidades de análisis y análisis del material.

${ }^{3}$ La distancia espacial resulta propia de la retórica etnográfica (Marcus y Cushman 1982) y se asocia a la idea del viaje en el trabajo de campo. Ir al lugar y observar directamente implica utilizar una estrategia de distanciamiento, donde dicho lugar aparece referido a través de una narrativa que destaca su carácter agreste e impenetrable, por tanto puro o salvaje.

${ }^{4}$ Nos referimos a la Revista de la Sociedad de Historia y Geografía (RHYG), la Publicación del Museo de Etnología y Antropología (PMEA), y el Boletín Museo de Historia Natural (BMHN). Por falta de recursos, entre 1910 y 1913 la Sociedad Chilena de Folklore logró publicar sólo tres tomos de la Revista de Folklore Chileno. En paralelo y con el objetivo de dar continuidad a la publicación de sus trabajos, estos se dieron a conocer en los Anales de la Universidad de Chile y, posteriormente, en la revista de la Sociedad de Historia y Geografía, ya como una de sus secciones.
${ }^{5}$ La primera sociedad científica creada en el país fue la Sociedad Arqueológica de Chile (1878-1880), y declaró entre sus líneas de trabajo el estudio de las lenguas americanas, sumando después la etnografía americana y las antigüedades americanas. Como consigna una nota publicada en el boletín del Museo de La Serena (1953), esta sociedad reunió a los intelectuales -historiadores, científicos y políticos- más sobresalientes de su tiempo.

${ }^{6}$ El análisis realizado permitió identificar un modelo localizable en la intersección de los polos ser/abstracto; cercano a esta ubicación podríamos situar la representación o auto-representación construida por Manuel Manquilef (1914)

7 Al respecto, Gusinde señalaba: "Acaso haya quienes nos objeten: ¡para que un Museo Etnológico y Antropológico! ¿Con qué objeto se gasta dinero en trastos viejos que no tienen valor práctico? ¿No se dice tal vez que debemos interesarnos únicamente por el futuro y dejar atrás el pasado, ya vencido por los inmensos progresos de la ciencia moderna?" (Gusinde 1916:36-37).

${ }^{8}$ En este sentido, algunos de estos primeros hombres de ciencia cuestionan las representaciones que circulan sobre el indígena, destacando sus cualidades y potencialidades. Sin embargo, dicha disputa no está acompañada de acciones que permitan instituir un punto de vista diferente, a partir del cual esta reconstrucción positiva cobre efectiva centralidad política, quedando relegada a una posición marginal.

${ }^{9}$ Para efecto de situar la posición de los autores se han tomado en consideración algunos casos, en particular los más representativos de cada modelo. 
